\title{
The American College of Surgeons: Challenges and Opportunities in a Global Environment
}

Tsoulfas G

\section{Introduction}

The American College of Surgeons (ACS) was established as a surgical society in 1913 in Chicago by Franklin Martin, MD, FACS with the goal of defining, promoting and safeguarding the highest standards of surgical care through education, training and ensuring an ethical practice environment [1]. As the ACS has grown over time, it has taken a position of leadership in defining the standards for surgery and surgical education in the US, and at the same time enjoying increasing global appeal. The result is over 80,000 members currently, with 6,600 of them being International Fellows and another 3,200 Associate Fellows (a category which includes young surgeons at the beginning of their surgical career, who by meeting certain standards have the opportunity to enjoy an active role in the College). All of this makes the ACS the largest association of surgeons in the world.

Along with this expansion, however, come increased responsibility and greater opportunities. Key among these is the increased international role of the ACS and the challenges and opportunities that this represents. The goal of this editorial is to present some of the different ways in which the ACS is extending its services to international surgeons and to contemplate what this could mean for our Hellenic Surgical Society.

\section{International Initiatives of the ACS}

Throughout the years several initiatives of the ACS have been aimed at strengthening the international presence of the College and providing its members with a more global perspective. These initiatives include:

1. Operation Giving Back (OGB): This is part of the Global Surgery effort. This has been paramount, given the change in the way that surgery is viewed by the World Health Organization (WHO), as shown by the May 2015 World Health Assembly (WHA) resolution. The realization came that when 2 billion people worldwide lack access to

Tsoulfas G, MD, PhD, FICS, FACS

Vice-Chair of the International Relations Committee of the ACS

President of the Greek Chapter of the ACS

Corresponding Authors: Tsoulfas Georgios, MD, PhD, FICS, FACS Associate Professor of Surgery, Aristotle University of Thessaloniki, Thessaloniki, Greece

e-mail: tsoulfasg@gmail.com surgical care, and 11-15\% of the global disease burden could be treated by surgery (malignancies, obstetric emergencies, trauma, congenital malformations), and the poorest third of the global population accounts for only 3.5\% of the 235 million major surgical operations, then it is time to reconsider the role of surgery as part of the basic, lifesustaining medical care. As a result, the $68^{\text {th }}$ WHA passed the resolution "Strengthening Emergency and Essential Surgical Care and Anesthesia in the context of Universal Health Coverage" [2].

The goal is for the ACS to develop a stronger and more formal involvement with the WHO. OGB has been a key part of the effort to identify surgical needs in underserved areas and to then use the resources of the College and its members to help meet those needs or, more importantly, to educate local people on how to meet those needs themselves.

2. The International Relations Committee (IRC): The role of the IRC has been greatly expanded in the last several years, with increasing involvement and activity on the part of the subcommittees, an increased presence at the Annual Congress, the introduction of educational packets providing standardized care, and scholarships and exchange programs, as shown below.

3. International Scholarships: There has been an impressive increase in the number of international travelling fellowships and exchange programs enabling international surgeons to visit surgical programs of their choice and at the same time offering the possibility to US surgeons to visit countries with long surgical traditions and interact with the surgeons there [3]. One of these scholarships is of special interest to Greek surgeons; the Niarchos Scholarship is specifically for surgeons of Greek origin.

4. ACS Regions and Regional Conferences: As part of the governance structure of the ACS, internationally there are groupings of countries into so-called "Regions". Each ACS Region, apart from the leadership of the national sections, also has a Governor. In the past several years there has been increased activity in several of these Regions, and especially in Region 15 (which includes Europe), where a "tradition" of annual conferences within the Region has been started, with international participation. This has forged increased communication, exchange of ideas and active collaboration between the various national sections, as shown by the most recent meetings in Portugal (2016) and Germany (2018).

5. The Value of International Membership: In recognition of the importance of the international membership, 
the ACS has attempted to define and showcase the value of ACS membership, both by getting feedback through surveys from the Fellows, and by making relevant information easily available on its website [4]. The goal has been to make International Fellowship accessible and to attract young members in training, with categories such as those for medical students and residents, while at the same time maintaining the prestige of an ACS Fellowship.

6. International Board of Governors: The Board of Governors is one of the more important structures of governance in the ACS, and the International Board of Governors is a manifestation of the importance of the international component and prospects of the ACS.

7. ACS Communities International: The ACS, as it continues to grow, is continuously seeking for ways to improve communication with the members. The ACS Communities serve as an electronic platform where Fellows can pose questions, ask for advice or share an experience or a thought, and get significant feedback from colleagues. The International ACS Community platform has the goal of increasing communication between the international Fellows themselves, as well as providing the US-based Fellows with exposure to what is happening in surgery around the world and what are the issues/challenges faced by surgeons in other countries, and their solutions.

8. Pon Fund: One of the more recent initiatives has been the Pon Fund. Specifically, Dr Pon Satitpunwaycha, through a most generous donation to the ACS, has established a fund which will allow international chapters to organize local educational courses suitable for the needs of the local surgeons. The twin goals of promoting surgical education in the international surgical community and encouraging the active involvement of the international chapters in ACS activities are both being met with the enthusiastic participation of several international chapters. The Greek ACS Chapter was one of the recipients of the Pon Fund, and in May 2017 the course "Global Surgery, Emergency Case Studies" took place in Athens with great success and the participation of several distinguished members of the ACS from the US, including Patricia Turner, MD, FACS, Director of Member Services of the American College of Surgeons, Richard Schulick, MD, MBA, FACS, The Aragón/Gonzalez-Gíustí Chair, Professor and Chair of Surgery at the University of Colorado School of Medicine, George Velmahos, MD, FACS, the John F. Burke Professor of Surgery, Harvard Medical School, Chair Division Chief of Trauma, Emergency Surgery and Critical Care, Massachusetts General Hospital, Boston, to name a few. Probably the greatest benefit for the course participants was the opportunity to interact with the international faculty and to start building meaningful relationships.

9. National Chapters and their educational efforts: The Pon Fund award for the organization of the educational course in May 2017 was only one of the many initiatives of the Greek ACS in the promotion of surgical education and provision of access to the ACS to many practising and future Greek surgeons. Other activities include the organization of the ACS General Surgery Review Course (which is similar to the 2-3 day course in the US, used as preparation for the American Surgical Board exams), ongoing educational lectures on various General Surgery topics, aimed mainly at residents and medical students, and several other congresses co-organized with Hellenic Medical Student Associations. Additionally, the Greek Chapter plays an active role in providing information on International Travelling Scholar Fellowships, including the Niarchos Scholarship.

10. International Surgical Leaders Forum (ISLF): The ISLF takes place at the Annual Congress of the ACS and serves as an opportunity for leaders from various national and international surgical associations from around the world to come together with the leadership of the ACS and learn about the international activities and goals of the ACS, as well as present their own goals and challenges. Most of all, it is an opportunity to identify common ground and areas of possible collaboration. The leadership of the Hellenic Surgical Association and the Governor of the Greek ACS Chapter have been consistently present in the ISLF.

\section{Where do we go now?}

We have seen some of the various different ways in which the ACS establishes its international presence and promotes the interests of both its US-based and its international Fellows. This is especially important today as we are experiencing the age of "Global Surgery". The key question, however, is what does all of this mean for us in Greece? Perhaps the best way to answer this is to consider this question as a challenge or an opportunity. Specifically, the role of the Greek Chapter of the ACS is critical in that it has the onus of extending the multiple opportunities presented by ACS membership to Greek surgeons, with special emphasis on the younger generation of medical students, surgical residents and young (or even young at heart) attending surgeons. An important step towards achieving this may be the interaction and active collaboration of the ACS with the Hellenic Surgical Association, which has a long-standing tradition of surgical excellence and an interest in cementing its international presence.

In a country where the daily challenges in the practice of surgery are continuously increasing, it is important to actively seek scientific, educational and clinical collaboration, so that we may all learn from each other. At the same time, this collaboration, and especially when it opens a window to the international stage, may also provide guid- 
ance and assistance to the future generations of young Greek surgeons, who are really the people (in addition of course to our patients) for whom we should be fighting and working.

\section{References}

1. Nahrwold D, Kernahan P. A Century of Surgeons and Surgery: The American College of Surgeons 1913-2012. Chicago, ACS 2012.
2. Price R, Makasa E, Hollands M. World Health Assembly Resolution WHA68.15: Strengthening Emergency and Essential Surgical Care and Anesthesia as a Component of Universal Health Coverage-Addressing the Public Health Gaps Arising from Lack of Safe, Affordable and Accessible Surgical and Anesthetic Services. World J Surg 2015;39:2115-25.

3. Nigri G, Early K, Tsoulfas G, et al. International Scholarship Programs of the American College of Surgeons: Expansion of the Global Surgical Network._World J Surg 2017 Oct 20. doi: 10.1007/s00268-017-4284-0.

4. ACS website: https://www.facs.org/. 2017 Nov 15. 